\title{
Irreverência e tradição em uma orquestra de tango: a versão como transgressão
}

\author{
María Eugenia Domínguez
}

Universidade Federal de Santa Catarina, Florianópolis, Brasil E-mail: eugison@yahoo.com 
Resumo

A apropriação de antigos temas musicais para elaborar novas canções é uma prática frequente tanto entre os artistas do Carnaval quanto entre os músicos de diversas cenas. Trata-se de versões que trazem uma nova letra para uma mesma música ou uma nova música para uma mesma letra, esses procedimentos contribuem na elaboração de sentidos de continuidade a partir da impermanência. Alguns artistas do Carnaval na região do Prata atribuem essa forma de composição à falta de formação acadêmica em música, em sintonia com os discursos de senso comum, que descrevem a murga como um gênero artisticamente menor. Mas como explicar essa forma de composição numa orquestra típica de tango (formato consagrado na história da música popular local e em que os músicos geralmente têm formação acadêmica em música)? A versão pode ser entendida nesse caso como um gesto irreverente em relação à concepção moderna em que a obra é uma entidade total e acabada em si mesma. As versões, especialmente, aquelas que traduzem músicas de um gênero para outro, podem ser pensadas como transgressões na medida em que desestabilizam os limites e as hierarquias que diferenciam gêneros e categorias sociais.

Palavras-chave: Versão. Tradição. Transgressão.
Abstract

The appropriation of old musical themes in order to create new songs is a frequent practice among carnival artists or musicians working in different musical scenes. These compositional procedures, which may envolve the articulation of new lyrics for the same music or a new music for the same lyrics, though based on unpermanency, may lead to senses of continuity. Some of River Plate's carnival artists explain this compositional procedure regarding to the lack of musical competence. So do many local common sense discourses in which murga is described as an artistically minor genre. But how could we explain this compositional procedure among tango "typical" orchestras (one of the most prestigious formations in local popular music, where musicians generally have formal instruction in music)? Cover versions may be understood here as an undisciplined gesture, considering modern conceptions which conceive of works of art as total and closed entities. Cover versions, especially those which translate musics from one genre to another, may be thought of as transgressions which undo limits and hierarchies between genres and social categories.

Keywords: Cover Version. Tradition. Transgression. 


\section{Apresentação $^{1}$}

Darte dos trabalhos recentes em torno do tango vem marcada pela irreverência dos músicos ou dançarinos em relação às convenções que pautavam as atuações tradicionais do gênero. Trata-se de mais um aspecto do movimento que alguns autores e autoras descrevem como uma "revitalização" do tango de Buenos Aires desde a última década do século XX (Moreno Chá, 1995; Olivieri, 2005).

A diversificação de âmbitos nos quais se dança tango e a proliferação de milongas ${ }^{2}$ dissidentes em relação a antigas moralidades (como o "tango nuevo", associado à cena do tango eletrônico, ou as milongas queer) são lidas por algumas autoras como uma ampliação de espaços para formas de sociabilidade até há pouco ausentes no universo do tango (Liska, 2009). Do "tango insolente" fala, por sua vez, Marta Savigliano (2011), ao refletir sobre os espetáculos de dança que se burlam dos estereótipos que exotizam o tango e, sobretudo, da sua índole passional.

Em relação às práticas musicais, podemos identificar propostas que, embora dialoguem com as formas de interpretação características nas orquestras da década de 1940 - referências paradigmáticas do "tango tradicional" -, não deixam de inscrever a marca das novas gerações em seus trabalhos. A aproximação do tango das estéticas de outros gêneros é uma estratégia criativa que permite articular a continuidade de aspectos tradicionais no gênero com outros renovadores (Garcia Brunelli, 2011a; Juárez, 2011a). Dando continuidade aos trabalhos sobre tais estratégias, a proposta deste texto é refletir sobre aquelas atuações ou gravações que desafiam as formas convencionais de interpretação no tango e, com elas, os limites do gênero. Tratarei 
especialmente dos arranjos ou das versões que aproximam músicas identificadas com diferentes cenas musicais ou que transformam músicas preexistentes para adaptá-las às prescrições de gêneros distintos daqueles em que a música foi previamente divulgada. A fim de observar comparativamente diferentes formas de versão-tradução, referir-me-ei às composições das murgas (conjuntos que atuam fundamentalmente no Carnaval de Buenos Aires e de Montevidéu) e de uma orquestra de tango de Buenos Aires. Na perspectiva proposta, a versão se configura como transgressão, na medida em que, ao traduzir músicas de um gênero para outro, se desnaturalizam as fronteiras e as hierarquias entre categorias sociais bem estabelecidas.

\section{Murgas, astracanadas e hierarquias estéticas}

Com o termo "versão" me refiro àquelas estratégias de composição que, como os arranjos, ${ }^{3}$ se apropriam de músicas preexistentes para elaborar novos temas. Na história da arte, o conceito de apropriação geralmente é utilizado em sentido formal, significando basicamente tomar elementos de um contexto e integrar em outro. Porém, desde a Filosofia e a Antropologia, o conceito de apropriação tem sido pensado como prática hermenêutica caracterizada como uma aprendizagem compreensiva através da qual os elementos adotam novos significados (Schneider, 2006). Através das práticas de apropriação, nessa perspectiva, tanto o objeto apropriado como o sujeito que se apropria se transformam.

De modo geral, a versão, seguindo a definição de Rubén López Cano (2011), é uma atualização em forma de gravação ou performance de uma canção ou tema instrumental que já foi interpretado ou gravado anteriormente. Ela pode ser pensada como a criação de um arranjador, mas também como experiência de escuta. Nessa perspectiva, a versão é também a elaboração, por parte dos ouvintes, de relações entre uma música considerada ponto de origem e outra que é compreendida como uma atualização. Nos casos em que a experiência de escuta não estabelece essa relação (por desconhecer a música anterior), a versão somente se realiza na sua dimensão histórica, mas não pragmática. O reconhecimento de uma música como versão de outra supõe que 1) 
existe pelo menos uma gravação ou performance anterior conhecida e reconhecida socialmente; 2) a canção se associa com o intérprete que realiza essa versão anterior, como com sua respetiva cena musical; 3 ) se constrói sobre o tema um sentido de pertencimento a esse intérprete; e 4) a nova versão introduz uma transformação na significação da peça (López Cano, 2011, p. 2).

Os usos e os significados dos termos "versão" e "arranjo" diferem de um contexto para outro, e, nos estudos sobre música popular, alguns autores propõem definições que os distinguem. ${ }^{4} \mathrm{Eu}$ os utilizo aqui de forma intercambiável, pois, entre os músicos de Buenos Aires ou entre aqueles que transitam entre a murga, o rock e o tango, eles são utilizados como sinônimos. Alguns admitem, porém, que na cena do tango é mais frequente o uso do termo "arranjo" para se referir a esse tipo de procedimento, enquanto na cena do rock se utiliza muito mais o termo "versão".

De qualquer modo, foi a partir do exame das práticas musicais e das versões das murgas de Buenos Aires ${ }^{5}$ que me aproximei e comecei a me interessar por esse assunto. Os murgueiros utilizam o termo astracanada para se referir à realização de músicas novas a partir de temas que foram divulgados pelas mídias, através do rádio ou do disco, ou de músicas de domínio público que foram transmitidas oralmente de geração em geração e que são amplamente reconhecidas pelas audiências no Carnaval.

A particularidade das astracanadas estaria no fato de tratar-se de um tipo de versão em que se articula uma nova letra para uma melodia preexistente. Trata-se de adaptações criativas para utilizar o conceito que Linda Hutcheon desenvolve em sua Teoria da adaptação (2011). As adaptações, na perspectiva da autora, são "revisitações deliberadas, anunciadas e extensivas de obras passadas" (Hutcheon, 2011, p. 15). E eu acrescentaria que são também anunciadoras da tradição, na medida em que selecionam o que passa a fazer parte da memória e o que será lembrado. Essa perspectiva construtivista em relação às tradições não deve, porém, fazer-nos esquecer que elas operam como "modelos de" e "modelos para" (Geertz, 1995): o fato de elas não serem naturalmente dadas, mas socialmente construídas, não as torna 
menos poderosas. As tradições descrevem e prescrevem, adquirindo muitas vezes um caráter normativo (Mendívil, 2004, p. 33), isto é, as diferentes tradições, através das suas comunidades de intérpretes, expressam o que se espera e se considera adequado para as atuações dos gêneros que as integram.

Nas diferentes tradições pode-se prescrever ou condenar, valorizar mais ou menos, a interpretação de repertório conhecido. Em âmbitos que se querem tradicionais, geralmente se valorizam bastante a interpretação de repertório antigo e o domínio dos estilos que caracterizam os gêneros ${ }^{6}$ desse universo. Neles predomina uma atitude retrospectiva. Agora, quanto mais moderno o artista ou quanto mais a renovação seja valorizada na comunidade de intérpretes que deseja integrar, mais será realçada a magnitude das mudanças introduzidas nas formas de interpretação e estruturas musicais dos trabalhos desenvolvidos. Nesses casos pode inclusive se obscurecer a continuidade no uso de algumas prescrições genéricas consideradas tradicionais. Continuidade e mudança aparecem como dois aspectos fundamentais a serem contrabalançados nas práticas musicais, cada iniciativa trazendo dosagem distinta deles, segundo os interesses e os hábitos dos músicos. Mas o que gostaria de realçar é que, inclusive nos casos em que se valoriza a reinterpretação de repertório tradicional, ela acaba, voluntária ou involuntariamente, por introduzir variações. A interpretação de repertório antigo desencadeia transformações de forma e de significados que decorrem tanto da nova contextualização como também da mensagem que os intérpretes procuram encaminhar através dessa interpretação. E se as variações podem ser introduzidas mais ou menos intencionalmente, dependendo do caso, é importante lembrar que os efeitos das práticas não necessariamente estarão associados com os objetivos dos músicos. Como vários antropólogos demonstraram, o exame da intencionalidade nas práticas, sejam musicais ou de qualquer outro tipo, nem sempre conduz à compreensão dos seus efeitos (Sahlins, 2003). Paradoxalmente, muitas mudanças advêm da intenção dos agentes em perpetuar a ordem social que conhecem.

Astracanada é um termo que, de algum modo, sintetiza a metáfora "gato por lebre". Mas, entre os murgueiros, o termo não conota 
ilegitimidade ou trapaça, muito pelo contrário: a competência poética para fazer astracanadas eficazes é uma habilidade muito valorizada. Trata-se de um procedimento compositivo que se registra nas murgas uruguaias, ${ }^{7}$ argentinas e gaditanas (isto é, de Cadiz, na Espanha) desde as primeiras décadas do século XX e que provavelmente é bem anterior. Nos Carnavais de diferentes latitudes é muito corrente a transformação de músicas preexistentes através da elaboração de novas letras para melodias conhecidas. Alguns autores utilizam o termo contrafacta para se referir a esse procedimento compositivo (Fornaro, 2002) que, especialmente nos Carnavais, subsidia performances de tom paródico. Muitos artistas do Carnaval com quem conversei atribuem essa forma de compor recorrente entre os conjuntos carnavalescos ao fato de que a maioria dos seus artistas não são "músicos" e não sabem "compor", o que os leva a se apropriarem de músicas já existentes.

Esse tipo de criação pode, certamente, ser pensado por meio da fórmula com a qual Claude Lévi-Strauss descreveu o pensamento mítico, entendendo-o como uma espécie de bricolagem intelectual que elabora novas construções a partir de elementos preexistentes, muitas vezes adotando-os para novos propósitos. Como se esclarece em El pensamiento salvaje:

el bricoleur es el que obra sin plan previo y con medios y procedimientos apartados de los usos tecnológicos normales. No opera con materias primas, sino ya elaboradas, con fragmentos de obras, con sobras y trozos (Lévi-Strauss, 1964, p. 35).

Em contextos individualistas, a composição que recolhe elementos preexistentes nas suas criações não parece tão legítima quanto a que cria formas novas. Muitas vezes os músicos utilizam esse critério para diferenciar, na criação artística, o âmbito folclórico-popular do erudito, lembrando as palavras de Lévi-Strauss (1964, p. 35) quando se refere aos meios do bricoleur como "desviados" em relação aos do homem de arte. O exame das versões na música popular nos permite compreender os procedimentos compositivos de muitos instrumentistas e cantores, que, ao partir de uma atitude retrospectiva, se aproximam das técnicas do bricoleur. Entre muitos músicos rio-platenses 
se valoriza a atitude retrospectiva como caminho para expressar "lo nuestro", a musicalidade "própria" da região. Isso não impede que a originalidade dos arranjos seja considerada importantíssima, marcando o que distingue algumas práticas de outras - e chegando ao ponto de descrever parte desse segmento como "música popular de calidad", uma qualidade medida com base na "sofisticação técnica" dos arranjos, classificando numa ordem hierárquica as respectivas práticas. ${ }^{8}$ As práticas dos músicos desse universo podem situar-se num contínuo: algumas mais próximas da tradição, representada por aqueles conjuntos formados majoritariamente por murgueiros ou candombeiros "del palo"9 - isto é, pessoas que fazem parte de murgas e blocos com atividade independente do universo musical -, outras mais próximas da inovação, representada por 'músicos' - ou seja, quem tem instrução formal em música. Estes se distinguem, na avaliação dos artistas com os quais tive ocasião de conversar, pela beleza e/ou sofisticação dos arranjos que realizam. Também vale destacar que as práticas mais próximas do polo inovador envolvem fundamentalmente música para escutar (em muitos casos, apenas instrumental), enquanto as práticas que orbitam em torno do polo tradicional se referem na maior parte das vezes à música para dançar ou para dançar e cantar. ${ }^{10}$ Assim, podemos observar que algumas práticas musicais se aproximam mais do polo inovador no qual se valoriza a criação individual e o que importa é a música propriamente dita; já nas práticas tradicionais o que conta é o que a música gera ou permite no encontro dos grupos. Nas reuniões em que se encaminham práticas associadas às murgas, a música é uma dentre as várias linguagens em jogo, e nesses casos uma música nova não tem mais eficácia que uma já conhecida. Mas, a meu ver, o fato de as músicas das murgas não serem produtos completamente originais, mas de segunda mão, contribui para que a sua arte seja desvalorizada e relegada às posições mais baixas nas hierarquias estéticas locais.

\section{Versão, transgressão e tradição em uma orquestra de tango}

Como sabemos, essa apropriação de temas preexistentes, nas diversas formas que ela pode assumir, não é um fenômeno restrito ao mundo do Carnaval, senão que perpassa a música popular. E por mais 
que se registre como um traço normal - isto é, não extraordinário -, o senso comum muitas vezes as condena como inferiores em relação à atividade criativa "autônoma" e "original" atribuída à composição. As adaptações são, em várias linguagens artísticas, consideradas secundárias e/ou dependentes em relação às obras "originais" (Hutcheon, 2011). As descrições das trajetórias de músicos e conjuntos nas crônicas muitas vezes anunciam, em tom evolutivo, a passagem daqueles períodos em que se interpreta repertório "alheio" para estádios mais "maduros" em que o artista desenvolve um repertório "próprio", “autoral". Nesse quadro, os valores modernos fazem com que as versões ou os arranjos, e com eles a prática da interpretação, sejam, de modo geral, considerados menores ou não tão nobres quanto a composição.

O exame de séries de transformações de uma mesma música é interessante na medida em que nos permite observar de perto processos de variabilidade cultural, em que o que está em jogo é a articulação entre continuidade e mudança, numa alquimia que não pode errar as doses de cada uma delas. Se por um lado os músicos e artistas do Carnaval compõem sob a exigência da elaboração do novo, como condição de continuar participando de outros Carnavais, de outros espetáculos ou de outras gravações, por outro lado essa novidade também não deve transcender certos limites se não quer deixar de se encaixar nas categorias com que organizamos a música e restar incompreendida. Nesse plano, a renovação se ajusta às medidas da continuidade de algumas prescrições que definem os gêneros. Essa continuidade que - nos discursos dos músicos e artistas do Carnaval - está na base do sentido de tradição é, no caso das versões, dos arranjos e das astracanadas, elaborada através de relações sonoras.

O fenômeno pode ser pensado à luz do conceito de intermusicalidade (Monson, 1996). Esse se refere não somente às relações objetivas entre séries de versões, mas fundamentalmente à atividade de escuta de um ouvinte particular. O conceito de intermusicalidade, tal como apresentado por Ingrid Monson (1996), envolve as relações auditivamente perceptíveis no contexto de tradições musicais particulares. ${ }^{11}$ Trata-se de um princípio que orienta as práticas interpretativas dos ouvintes como também a atividade dos músicos. ${ }^{12}$ Reconhecer relações nos permite fazer parte de uma comunidade de intérpretes; elaborar 
tais relações através de versões é também uma forma de provocar ou apelar, mesmo que não intencionalmente, a esse reconhecimento.

Andava nessas indagações quando, em 2006, fazendo pesquisa de campo em Buenos Aires, fui assistir ao show da Orquestra Típica Fernández Fierro. ${ }^{13} \mathrm{O}$ recorte dessa pesquisa se centrava nos trabalhos musicais que, de alguma forma, atravessavam a separação entre o uruguaio e o argentino, aproximando tango, milonga, candombe uruguaio e argentino, e murga urguaia e argentina. (Com essa tendência convive, tensamente, outra que cria e recria tanto essa separação quanto diferenças que a reafirmam. ${ }^{14}$ ) E esse não era, certamente, o caso da orquestra, que até então tocava fundamentalmente repertório da "época de ouro" do tango, isto é, composições das décadas de 1940 e 1950 (Juárez, 201 la). Qual não foi a minha surpresa quando anunciaram que, para encerrar o show, apresentariam um tema de seu próximo $C D$, inédito ainda nesse momento, que era nada menos que uma versão realizada a partir de dois temas: Las luces del estadio, composta pelos uruguaios Jaime Roosa ${ }^{15}$ e Raúl Castro, ${ }^{16}$ e Buenos Aires hora 0, do compositor argentino Astor Piazzolla ${ }^{17}$. A versão acabou se tornando potente no repertório da orquestra; prova disso é que, até hoje (2012) e mesmo tendo lançado mais um CD em 200918, eles continuam a encerrar os shows com aquele tema gravado em 2006. ${ }^{19}$

A versão da Orquestra Típica Fernández Fierro chamou a minha atenção, pois, familiarizada com as astracanadas, isto é, versões em que se cria uma nova letra para uma música conhecida, estava agora frente a outro tipo de versão em que a letra conhecida é mantida, criando-se uma música diferente daquela com que o tema foi divulgado. Como vimos, são correntes na murga portenha, gênero grotesco e mistongo, ${ }^{20}$ as versões que através de novas letras articulam temas identificados com cenas musicais diversas. ${ }^{21}$ Também sabemos que, no juízo de muitas pessoas de Buenos Aires, a murga argentina é musicalmente um gênero menor (inclusive para muitos murgueiros, para quem isso não é necessariamente um problema), dentre outras coisas, devido a esse seu procedimento compositivo característico e também ao fato de que sua música é mais para dançar do que para escutar. Então, como explicar agora sua aparição numa orquestra típica de tango, uma das formas mais consagradas na interpretação da música popular na Argentina? 
Buenos Aires hora 0 é um tango criado por Piazzolla na época do Quinteto Nuevo Tango nos anos 1960 e que já recebeu inúmeros arranjos. Já Las luces del estadio é um caso especial porque tem mais de um original: o compositor e o letrista (ambos autores "originais") a interpretam segundo as pautas de gêneros distintos.

Raúl "Tinta Brava" Castro, o letrista, que é diretor da murga uruguaia Falta y resto, interpreta o tema com a murga. ${ }^{22}$ Suas atuações reproduzem as pautas da murga uruguaia, embora o desloquem para a interface com a "canção popular". Isso porque, nos últimos vinte anos, alguns conjuntos murgueiros tanto no Uruguai quanto na Argentina vêm compondo temas rotulados como "murga canção", nos quais geralmente introduzem arranjos e instrumentos considerados estranhos à murga uruguaia ou à murga argentina. Na música em questão observa-se esse tipo de inovação no acompanhamento com violão todo ao longo do tema, quando na murga uruguaia, até recentemente, o violão era somente utilizado pelo diretor para marcar o tom aos cantores ao início das músicas, mas não para acompanhá-las na íntegra. ${ }^{23}$

De qualquer modo, o "original" 24 que se tornou versão de referência para a orquestra típica de tango cuja versão examino não é a performance da murga, mas a versão do compositor, Jaime Roos, que já a gravou e a reeditou em alguns CDs. Jaime Roos, sempre vale a pena lembrar, é um músico de grande renome na cena do rock uruguaio que, desde a década de 1980, atua com frequência na Argentina e que, como muitos roqueiros dessas latitudes, já compôs tangos memoráveis. Las luces del estádio é interpretado por Roos e seu conjunto com violão eletroacústico, guitarra, baixo elétrico, teclado e bateria, além da voz do cantor. ${ }^{25}$

Na versão da orquestra as duas peças que servem de base ao arranjo são tratadas diferentemente. Las luces del estadio mostra bastante continuidade com a versão anterior, continuidade que ultrapassa o que seria estritamente a letra, pois ela ainda se ajusta aos contornos melódicos da música de referência. Já Buenos Aires hora 0 é apropriada com mais liberdade, sendo completamente reorganizada. É basicamente através das alusões a Buenos Aires hora 0 e ao motivo que a caracteriza que Las luces del estadio se transforma num tango riff. O tema abre com 
o riff que o identifica e que se repete com variações ao longo da peça, intercalado com estrofes. ${ }^{26}$ Nas palavras do arranjador, Yuri Venturín, contrabaixista e diretor de orquestra, é como se Las luces del estadio fosse a casa e Buenos Aires hora 0, a decoração. Tango riff é um conceito da orquestra que se refere àquelas composições que podem em diferentes medidas continuar as formas interpretativas do tango tradicional, por exemplo, se apropriando do estilo de Osvaldo Pugliese, ${ }^{27}$ mas onde a organização do tema se aproxima mais de algumas vertentes do rock. ${ }^{28}$ Fora as transformações estritamente "musicais" que o arranjador descreveu ao explicar a sua versão pra mim (Venturín, 2012), a experiência de escuta ${ }^{29}$ da versão da orquestra revela a apropriação de uma música que se tornou conhecida na cena do rock - movimento que nas décadas de 1970 e 1980 se queria contracultural, renegando, dentre outras coisas, do conservadorismo da cena do tango (Pujol, 2005). Por sua vez, alude-se explicitamente a uma música representativa das sonoridades dissidentes que Piazzolla incorpora no mundo do tango, abrindo uma brecha com as orquestras mais tradicionais. O Quinteto Nuevo Tango de Piazzolla incluía instrumentos e arranjos considerados alheios ao mundo do tango até então, por remeterem diretamente aos universos do rock e do jazz (Garcia Brunelli, 2011b).

Não que essa orquestra não tivesse arranjado tangos preexistentes antes: seus primeiros discos, de fato, trazem quase exclusivamente arranjos de tangos antigos, compostos maiormente antes de 1960, consagrados como genuínos representantes do gênero. O que no caso faz a diferença é como foi feito o arranjo, a sua poética (Eco, 1976). Ela nos fala de um projeto de trabalho dos artistas, como explicava Umberto Eco (1976, p. 24) em Obra aberta:

Nós entendemos poética num sentido mais associado à acepção clássica: não como sistema de regras coercitivas (a Ars Poética como norma absoluta), mas como programa operacional que o artista se propõe de cada vez, o projeto de obra a realizar tal como é entendido, explícita ou implicitamente, pelo artista.

Penso que é nos dois últimos albumes da orquestra (quinto e sexto da sua discografia) que se registra com mais clareza o que pode ser 
pensado como uma poética transgressora. O arranjo Las luces del estadio/ Buenos Aires hora 0 é o tema final do primeiro; o segundo traz, por sua vez, uma versão que transforma uma antiga música (Una larga noche) da cantora e compositora peruana Chabuca Granda (1920-1983) num tango riff. Entre ambas as versões pode ser identificada uma continuidade estilística que se revela na articulação de elementos associados a diferentes cenas musicais. Portanto, o procedimento marca presença justamente no período em que o conjunto exprime uma produção mais "autoral" (termo que nos estudos musicais se utiliza para se referir a um estilo "próprio"). Como descreve Camila Juárez (2011a), os 10 anos de existência da orquestra podem ser divididos em dois grandes períodos. Durante os primeiros cinco anos de existência, como muitos outros conjuntos que fazem parte do mesmo movimento (Juárez, $201 \mathrm{lb}$ ), interpretava fundamentalmente releituras da obra de Osvaldo Pugliese, Alfredo Gobbi ${ }^{30}$ e Juan D'Arienzo. ${ }^{31}$ Seria essa uma fase “historicista" ou de continuidade com o passado do tango. Já a partir de 2005, ano em que lançam Mucha Mierda - seu quinto CD - e a faixa sob exame, a orquestra passa a incluir no repertório, além de algum tango clássico, composições de músicos contemporâneos (como Alfredo Tape Rubín), outras assinadas por músicos da orquestra - que estão na faixa dos trinta anos, não muito consagrados -, algumas em parceria com artistas renomeados na cena do rock como Palo Pandolfo e arranjos que articulam referências a peças que não se associam ao repertório tradicional do tango. Não se trata agora de releituras dos clássicos representantes do gênero, mas de músicas divulgadas em outras cenas musicais, como o rock ou a canção "criolla" peruana. Dessa forma, ao convidar-nos a ouvir (e pensar) a música para além dos limites entre os gêneros, atentando para o que acontece nos entregêneros (Holt, 2008), a orquestra também realiza comentários sobre o tango que não muda, sobre o tango com contornos e limites bem definidos e sobre as hierarquias que organizam a classificação dos gêneros localmente. O estudo de versões que traduzem músicas de um gênero a outro revela que, às vezes, as variações são introduzidas com o objetivo de desafiar os limites do gênero. Na medida em que esses representam o poder da convenção na estruturação do social, desafiá-los é uma forma de 
contestar tais estruturas. Tal como aponta Susan McClary ( 1991 apud Ochoa, 2003, p. 86):

Los géneros musicales y las convenciones se cristalizan porque son aceptados como naturales por una cierta comunidad: definen los límites de lo que cuenta como un comportamiento musical apropiado. Pero la cristalización o legislación también hace que esas normas estén disponibles para ser rotas, haciendo que la música se constituya en un terreno en el cual las transgresiones y las oposiciones pueden ser registradas directamente.

Dando continuidade à ideia inicial de que a tradição supõe processos de mão dupla, gostaria de propor que há nesse tipo de versão um retorno sem regressão - como diria Linda Hutcheon (2011, p. 232) -, articulado através de um gesto de transgressão. Os temas que os músicos realizam - sejam composições ou versões - podem ser entendidos como enunciados tendentes a estabilizar ou desafiar os limites dos gêneros, bem como a manter ou refazer as relações hierárquicas entre eles. Aqui as ideias de Mikhail Bakhtin (1982 e 1991) podem ser inspiradoras por permitirem pensar a música como um sistema de gêneros no qual coexistem forças centrípetas e centrífugas. As centrípetas tendem à centralização, unificação, estandardização, hegemonia; as centrífugas, à descentralização, divisão e competição entre múltiplas vozes sociais (Duranti, 2000, p. 113-114). Se pensadas como enunciados, as canções expressam uma combinação dessas forças. Na hipótese de que as versões sejam realizadas num gênero distinto do que popularizou a canção de referência e inclusive quando as prescrições de diferentes gêneros são reunidas numa mesma canção, pode-se pensar em termos de forças centrífugas, que transgridem as normas definidoras do que se espera da performance num gênero particular.

Ao evocar esses procedimentos, penso na irreverência que supõe esse distanciamento do paradigma moderno em que a obra é uma entidade total, acabada em si mesma (cf. Eco, 1976). Trata-se de versões que trazem uma nova letra para uma mesma música ou uma nova música para uma mesma letra, esses procedimentos contribuem na elaboração de sentidos de continuidade a partir da impermanência. Quem me chamou a atenção para esse ponto foi o próprio arranjador, 
que me explicou que, quando comparada com as músicas de referência, a sua versão de Las luces del estadio "[...] es muy diferente, pero no es otra cosa" (Venturín, 2012). Mais do que ruptura, temos aqui uma estratégia que permite sair da tradição para nela entrar novamente. ${ }^{32}$ As versões se encadeiam temporalmente, permitindo imaginar uma tradição de canções, observando-se também que cada uma faz sentido pela canção anterior que ela não é. A irreverência que o gesto exprime nos fala do caráter eminentemente social da música, em que uma versão pode ser uma transgressão e, ainda assim, atualizar os afetos da tradição.

\section{Notas:}

1 Uma versão anterior deste trabalho foi apresentada no X Congresso da Associação Internacional para o Estudo da Música Popular (IASPM-LA) em abril de 2012 e publicada (em espanhol) nos anais do evento.

2 Por milongas me refiro aos espaços onde se dança tango.

3 Para uma reflexão sobre os limites entre arranjo e composição, veja Menezes Bastos (no prelo).

4 Remeto ao texto de Rubén López Cano (2011) para uma classificação dos diferentes tipos de versão.

5 As murgas de Buenos Aires são conjuntos artísticos que atuam fundamentalmente nos Carnavais da cidade. Desde a década de 1990, as murgas estenderam seu calendário de atuações, apresentando-se em festas e espetáculos em qualquer época do ano. No mesmo período, as murgas começaram a gravar seus repertórios em CDs. Para um estudo sobre as transformações recentes no campo murgueiro, remeto a Martín (2008).

6 Penso o conceito de gênero me apropriando da proposta de Bakhtin (1982) para pensar os gêneros discursivos, entendendo-os como conjuntos de enunciados relativamente estáveis nos planos estrutural ou compositivo, temático e estilístico ou interpretativo.

7 Os murguistas uruguaios, à diferença dos murgueiros argentinos (uns e outros utilizam esses diferentes substantivos para se referir a si mesmos e às pessoas que se dedicam à murga uruguaia e à murga argentina, respetivamente, que são, na minha perspectiva, gêneros distintos), não utilizam o termo astracanada para se referir a esse tipo de versão, por mais que o procedimento envolvido seja o mesmo.

8 Esta "sofisticação técnica" se relaciona com o domínio, por parte dos compositores e arranjadores, de saberes da chamada "música erudita", tais como harmonia, contraponto etc., acessíveis fundamentalmente para quem tem instrução formal em música em conservatórios ou em escolas de música.

9 Na fala de Buenos Aires muitas vezes se utiliza a expressão "ser del palo" no sentido de pertencer a alguma comunidade. Palo tem um significado distinto no espanhol e no lunfardo rio-platense. No dicionário etimológico do lunfardo se define como "Grupo con una comunidad de intereses o gustos"; "Ser del mismo palo: tener gran afinidad con otro o pensar de modo semejante; pertenecer a un mismo grupo" (Conde, 2004, p. 241-242). 
${ }^{10}$ Esta distinção já foi utilizada para descrever as diferenças entre o que, nos textos anglo-saxões, é referido como "high art" e "low art". Ao descrever as ideias da Escola de Frankfurt - especialmente de Adorno e Horkheimer -, Simon Frith (1996, p. 18) examina a presumida distinção entre "the 'autonomy' of high art (which exists only for 'artistic reasons', it's value, therefore, an effect of its form) and the 'function' of low art, which exists to serve some end (commercial, hedonistic) and is valued accordingly, by reference not to its internal features but to its use".

${ }^{11}$ Rubén López Cano (2007, p. 30-31) discorre sobre a "intertextualidade musical" para se referir ao mesmo tipo de fenômenos que podem ser pensados através do conceito de intermusicalidade. Retomo, porém, a proposta de Ingrid Monson (1996) para realçar o fato de que se trata aqui de referências sonoras.

12 Isto por mais que a atividade do intérprete enquanto "executante" (o instrumentista ou o cantor que executa ou interpreta uma peça musical) difere da de um intérprete enquanto fruidor (quem ouve uma peça musical executada por outrem). A esse respeito é esclarecedora a explicação de Umberto Eco (1976, p. 39): “Contudo [...] vale encarar ambos os casos como manifestações diversas de uma mesma atitude interpretativa: cada 'leitura', 'contemplação', 'gozo', de uma obra de arte representam uma forma, ainda que calada e particular, de 'execução'. A noção de processo interpretativo abrange todas essas atitudes".

13 "Orquestra típica" é a denominação que se utiliza no mundo do tango para se referir a conjuntos que, com pequenas variantes, incluem uma fila de bandoneons (dois, três ou quatro), uma fila de cordas (dois, três ou quatro violinos, viola, violoncelo e contrabaixo) e piano. Podem ou não incluir cantor. Como descreve Sierra (1985), a formação da orquestra típica foi mudando ao longo do século XX, até se estabilizar (estabilidade que sempre será relativa) nessa formação.

14 Desenvolvo esta ideia em Suena el rio (Domínguez, 2009), meu trabalho de doutorado.

${ }^{15}$ Cantor, violonista e compositor (Montevidéu, 1953-).

16 Cantor, compositor e letrista de murga (Montevidéu, 1950-).

17 Bandoneonista, pianista, compositor e diretor (Mar del Plata, 1921-Buenos Aires, 1992).

18 Orquestra Típica Fernández Fierro, Fernández Fierro, 2009 (edição da Orquestra Típica Fernández Fierro).

19 Orquestra Típica Fernández Fierro, Mucha Mierda, 2006 (edição da Orquestra Típica Fernández Fierro).

20 Termo do lunfardo rio-platense que significa "pobre, humilde, de pouco valor" (Conde, 2004, p. 222).

${ }^{21}$ Por citar um exemplo, Gustavo Masó, letrista da murga Los duendes de caballito, declarou ter feito astracanadas a partir de canções de Pink Floyd, Astor Piazolla, Beatles (do musical Hair), Joan Manuel Serrat, Sandro, Victor Heredia, Gabi-Fofó e Miliqui (especificamente o clássico infantil La gallina turuleca), além de uma em ritmo de som cubano e uma cúmbia. Já o Haka nacional, presente no CD Carnaval Porteño (v. l) e muito difundido nos meios de comunicação durante a Copa Mundial de Rúgbi de 2007, é uma astracanada baseada no canto dos jogadores da seleção de rúgbi da Nova Zelândia, os quais se apropriaram, por sua vez, de um canto aborígene (entrevista concedida à autora, Buenos Aires, 17 mar. 2006).

22 A atuação da murga está disponível em < http://www.youtube.com/watch?v=Lg5w3qeyg-U>. 
${ }^{23}$ No formato "tradicional" integram a murga uruguaia os cantores (geralmente em torno de 15) e três instrumentistas: um no bombo de murga, um na caixa e mais um que executa pratos de mão.

24 "Original" está aqui entre aspas, pois o estudo dos arranjos na música popular nos coloca frente à dispersão do original (López Cano, 2011). No caso em questão não há uma, mas duas ou três músicas originais. De qualquer modo, é uma delas - a que foi gravada por Roos, e não a performance da murga Falta y resto - a que se tornou canção de referência da versão sob exame.

25 A performance está disponível em <http://www.youtube.com/watch?v=0OzF6DEud l 8 \&feature $=$ related $>$.

${ }^{26}$ A música e o vídeo de uma atuação estão disponíveis em $<$ http://www.fernandezfierro.com/discos.php?lang $=\mathrm{pt}>$.

27 Pianista, compositor e diretor (Buenos Aires, 1905-1995).

${ }^{28}$ Camila Juárez (201 la) analisa esse tipo de estrutura compositiva utilizando como exemplo as composições da banda inglesa AC/DC.

${ }^{29}$ Lembrando sempre que a experiência de escuta está ancorada em histórias auditivas que fazem parte de processos históricos, não dependendo exclusivamente das nossas emoções ou psicologias individuais (Feld, 1994 apud Mendívil, 2004, p. 30-31). Em outras palavras, a proposta é pensar a escuta como uma técnica corporal (Mauss, 2003 ) que depende de processos biológicos, psicológicos e, fundamentalmente, sociais.

${ }^{30}$ Violinista, compositor e diretor (Paris, 1912-Buenos Aires, 1965).

31 Violinista, compositor e diretor (Buenos Aires, 1900-1976).

32 Estou parafraseando o título do artigo de Mendívil, Huaynos híbridos: estrategias para entrar y salir de la tradición (2004), explicitamente se apropriando da fórmula de Garcia Canclini (Culturas híbridas: estrategias para entrar y salir de la modernidad).

\section{Referências}

BAKHTIN, Mickail. El problema de los géneros discursivos. In: Estética de la creación verbal. Mexico: Siglo XXI, 1982. p. 245-290.

. Discourse in the Novel. In: HOLQUIST, Michael (Ed.). The Dialogic Imagination: Four Essays. Austin: University os Texas Press, 1991.

CONDE, Oscar. Diccionario etimológico del lunfardo. Buenos Aires: Taurus, 2004.

DOMÍNGUEZ, María Eugenia. 2009. Suena el río. Entre tangos, milongas, murgas e candombes: músicos y gêneros rio-platenses em Buenos Aires. Tese (Doutorado em Antropologia Social) - Universidade Federal de Santa Catarina, Florianópolis, 2009.

DURANTI, Alessandro. Antropologia linguistica. Madrid: Cambridge University Press, 2000.

ECO, Umberto. Obra aberta. São Paulo: Perspectiva, 1976. 
FARACO, Carlos Alberto. Autor e autoria. In: BRAIT, Beth (Org.). Bakhtin: outros conceitos-chave. São Paulo: Contexto, 2007. p. 37-60.

FELD, Steven. Communication, Music, and Speech about Music. In: FELD, Stephen; KEIL, Charles. Music Grooves. Chicago/Londres: University Chicago Press, 1994. p. 77-95.

FORNARO, Marita. Los cantos inmigrantes se mezclaron. TRANS: Revista Transcultural de Música, Barcelona, n. 6, 2002.

FRITH, Simon. Performing Rites: On the Value of Popular Music. Cambridge: Harvard University Press, 1996.

GARCIA BRUNELLI, Omar. El tango actual: estrategias musicales para articular tradición con un enfoque contemporáneo. Revista Afuera, Buenos Aires, n. 10, maio 201 la. Dossier Arte Sonoro: las Ciencias Sociales a a la escucha del tango. Disponível em: < http://www.revistaafuera.com/seccion. php?id $=458$ nro $=10>$. Acesso em: 16 maio 2012.

. La incorporación del jazz a la trama del tango en la música de Astor Piazzolla. In: COLLOQUE INTERNATIONAL TANGO: CRÉATION/ IDENTIFICATION/CIRCULATION, 201 l, Paris. Anais... Paris, $201 \mathrm{lb}$. Disponível em: < http://globalmus.net/IMG/mp3/27_omar_garcia_brunelli_ salle7.mp3>. Acesso em: 16 maio 2012.

GEERTZ, Clifford. La interpretación de las culturas. Barcelona: Gedisa, 1995.

HOLT, Fabian. A View from Popular Music Studies: Genre Issues. In: STOBART, Henry (Ed.). The New Ethnomusicologies Europea: Ethnomusicologies and Modernities $n^{\circ}$ 8. Maryland: The Scarecrow Press, 2008. p. 40-47.

HUTCHEON, Linda. Uma teoria da adaptação. Florianópolis: Ed. UFSC, 2011.

JUÁREZ, Camila. Orquesta Típica Fernandez Fierro: la renovación del tango através de una típica. In: COLLOQUE INTERNATIONAL TANGO: CRÉATION/IDENTIFICATION/CIRCULATION, 2011, Paris. Anais... Paris, 201 la. Disponível em: < http://globalmus.net/IMG/mp3/27_camila_juarez_ salle7.mp3>. Acesso em: 16 maio 2012.

. El surgimiento de las jóvenes orquestas de tango en los años noventa. Dos casos de estudio: el arranque y la máquina tanguera. Revista Afuera, Buenos Aires, n. 10, $201 \mathrm{lb}$. Dossier Arte Sonoro: las Ciencias Sociales a a la escucha del tango.

LÉVI-STRAUSS, Claude. El pensamiento salvaje. Mexico: Fondo de Cultura Económica, 1964.

LISKA, Maria Mercedes. El tango como disciplinador de cuerpos ilegítimos-legitimados. TRANS: Revista Transcultural de Música, Barcelona, n. 13, 2009. 
LÓPEZ CANO, Rubén. Música e intertextualidad. Pauta: Cuadernos de Teoría y Crítica Musical, n. 104, p. 30-36, 2007.

. Lo original de la versión: de la ontologia a la pragmática de la versión en la música popular urbana. Consensus, n. 16, p. 57-82, 2011.

MARTÍN, Alicia. Política cultural y patrimonio imaterial en el Carnaval de Buenos Aires. Ilha: Revista de Antropologia, Florianópolis: Ed. UFSC, v. 8, n. 2, p. 295-314, 2008.

MASÓ, Gustavo. Entrevista concedida à autora. Buenos Aires, 17 mar. 2006.

MAUSS, Marcel. As técnicas do corpo. In: Sociologia e Antropologia. São Paulo: Cosac \& Naify, 2003. p. 401-424.

MCCLARY, Susan. Introduction: A Material Girl in Bluebird's Castle. In:__. Feminine Endings: Music, Gender and Sexuality. Minnesota: University of Minnesotta Press, 1991. p. 3-34.

MENDÍVIL, Julio. Huaynos híbridos: estrategias para entrar y salir de la tradición. Lienzo, n. 25, p. 27-64, 2004.

MENEZES BASTOS, Rafael José de. Conflito, lamentação e irrisão na Música Popular Brasileira: um estudo antropológico sobre a Saudosa Maloca de Adoniran Barbosa. Por que as canções têm Arranjos? No prelo.

MONSON, Ingrid. Saying Something: Jazz Improvisation and Interaction. Chicago: Chicago University Press, 1996.

MORENO CHÁ, Ercilia. Prólogo. In: (Comp.). Tango tuyo, mio $y$ nuestro. Buenos Aires: Instituto Nacional de Antropologia y Pensamiento Latinoamericano, 1995. p. 5-15.

OCHOA, Ana Maria. Músicas locales en tiempos de globalización. Buenos Aires: Norma, 2003.

OLIVIERI, Marcelo Hector. El tango del tercer milenio. Buenos Aires: Ediciones del Cachafaz, 2005.

PUJOL, Sergio. Rock y dictadura: crónica de una generación - 1976-1983. Buenos Aires: Emecé, 2005.

SAHLINS, Marshall. Ilhas de História. Rio de Janeiro: Jorge Zahar Editor, 2003.

SAVIGLIANO, Marta. Tangos insolentes. In: COLLOQUE INTERNATIONAL TANGO: CRÉATION/IDENTIFICATION/CIRCULATION, 2011, Paris. Anais... Paris, 2011. Disponível em: < http://globalmus.net/IMG/mp3/271011_ marta_savigliano.mp3>. Acesso em: 16 maio 2012. 
SCHNEIDER, Arnd. Appropriation as Practice: Art and Identity in Argentina. New York: Palgrave Macmillan, 2006.

SIERRA, Luis Adolfo. Historia de la Orquesta Típica: evolución instrumental del tango. Buenos Aires: Corregidor, 1985.

VENTURÍN, Yuri. Entrevista concedida à autora. São Paulo, 24 mar. 2012.

Recebido em 02/06/2012

Aceite em 30/06/2012 